\title{
The Flux, Pulse, and Spin of Aggression-Related Affect
}

\author{
in press at Emotion
}

\author{
David S. Chester ${ }^{1 *}$, Malissa A. Clark², C. Nathan DeWall ${ }^{3}$ \\ ${ }^{1}$ Department of Psychology, Virginia Commonwealth University, USA \\ ${ }^{2}$ Department of Psychology, University of Georgia, USA \\ ${ }^{3}$ Department of Psychology, University of Kentucky, USA
}

${ }^{*}$ Correspondence should be addressed to:

David S. Chester

302 Thurston House

Virginia Commonwealth University

Richmond, VA, 23284, USA

$1-804-828-7624$

dschester@vcu.edu

Research reported in this publication was supported by the National Institute on Alcohol Abuse and Alcoholism (NIAAA) of the National Institutes of Health under award K01AA026647 (PI: Chester). 


\begin{abstract}
Aggression is an affect-laden behavior. The within-person variability of affective states that immediately precede, accompany, and follow aggression — and their links to between-person variability in aggressive behavior and traits - remain incompletely understood. To address this gap in our understanding, we examined eight studies in which 2,173 participants reported the negative and positive affect they experienced before, during, and after a laboratory or online aggression task. We quantified the within-person variability within (flux) and across (pulse) negative and positive affect intensity, as well as the variability in oscillations between negative and positive affect (spin). Internal meta-analyses revealed an association between aggressive behavior and traits and flux in positive affect (against our preregistered predictions). Probing this effect with piecewise growth models showed that less aggressive individuals exhibited a pronounced decrease in positive affect during aggression, as compared to before and after the act. This downward fluctuation in positive affect was attenuated among aggressive individuals, who exhibited relatively stable levels of positive aggressionrelated affect. Thus, stable positive affect surrounding an aggressive act and higher positive affect during the act may buttress and promote aggressive tendencies. These findings support a reinforcement model of aggressive behavior, contrast with the aggression literature's conventional focus on negative affect and the instability thereof, and point to the utility of dynamic measures of moment-to-moment affect in understanding human social behavior.
\end{abstract}

Keywords: affect, aggression, emotion, flux, pulse 


\section{Introduction}

Affect is the prime candidate that psychologists have used as a proximate explanation for why people act aggressively (Anderson \& Bushman, 2002; Berkowitz, 1989; Ramirez \& Andreu, 2006). Yet our understanding of the affective bases of aggression remains incomplete. Though many studies have examined how aggression is linked to affective instability - such research has focused on longer timeframes that span days, months, and years. What these studies fail to grasp is how affect rapidly varies in the moments before, during, and after an aggressive act. This investigation sought to fill this gap in the literature. To that end, we re-analyzed eight existing datasets to examine this under-studied link between aggression and the dynamics of individuals' aggression-related momentary affect.

\section{Affect: Definition and Disambiguation}

Affect is a physiologically-grounded perceptual process that transiently fluctuates across time and situations and also changes due to environmental stimuli (Barrett \& Bliss-Moreau, 2009; Barrett \& Russell, 1999; Russell, 2003). We refer to affect as an affective state (not a dispositional affective trait) when discussing it in relation to a discrete period of time, a discrete event, or a discrete affect assessment. Such affective states are experienced as a mixture of aversive (i.e., negative) and pleasant (i.e., positive) valences (Tellegen, Watson, \& Clark, 1999). In addition, affective states vary along a high-to-low arousal dimension and can range from subconscious states to consciously-aware episodes (Barrett \& Bliss-Moreau, 2009; Barrett \& Russell, 1999). An affective state can be thought of as a broader concept that can be further broken down into emotions, which are conscious episodic experiences that are constructed from 
more psychologically primitive affective states and attributed to an external cause, Barrett, 2009; Russell, 2003). Affect can also exist as moods, which are affective states that do not require such conscious perception or external attribution and typically occur over relatively longer periods of time than emotions (Russell, 2003). In the present research, we focus on transient affective states—broadly speaking — that are associated with aggressive behavior. Although the term feelings is sometimes used to describe an affective state, this term is not used in the present study because it is used rather colloquially and also includes non-affective somatosensory and interoceptive sensations. Affective states have a long tradition in the study of the causes of aggressive behavior.

\section{Affective Bases of Aggression}

Affect has a long history as putative causes of aggressive behavior and dispositions. Such characterizations date back (at least) to the Freudian proposal that aggression arises from a cathartic release of negative affect (Bushman, 2002). This tradition continues, with many studies examining how experimentally-induced affective states and dispositional affective tendencies influence aggressive behavior (Anderson \& Bushman, 2002; Berkowitz, 1989; Ramirez \& Andreu, 2006). However, these studies have largely focused on between-person differences in affect and not on the dynamic, within-person fluctuations in affective states.

\section{Measuring Affective Dynamics: From Long-Term to Momentary Variability}

Affective experiences vary over both long and short timeframes, ranging from transient states to dispositional traits. To capture affective variability across longer and shorter temporal ranges, researchers adopt different methods (Figure 1). At one 
extreme of this spectrum, researchers examine individuals' affective variability over years, months, or weeks of longitudinal affective assessments (i.e., variability in a person's general affective disposition), and still others have participants complete daily affect diaries to examine day-to-day fluctuations in affect (i.e., variability in a person's affective state; e.g., McNulty \& Hellmuth, 2008). An even more granular, detailed approach to affective variability is to make repeated affect assessments within a single day (as in ecological momentary assessment studies) or before, during, and after a specific laboratory experience (e.g., Chester \& DeWall, 2017). These varying levels of investigation have often been applied to the study of aggression.

Figure 1. Varying levels of temporal granularity in approaches to studying affect variability.

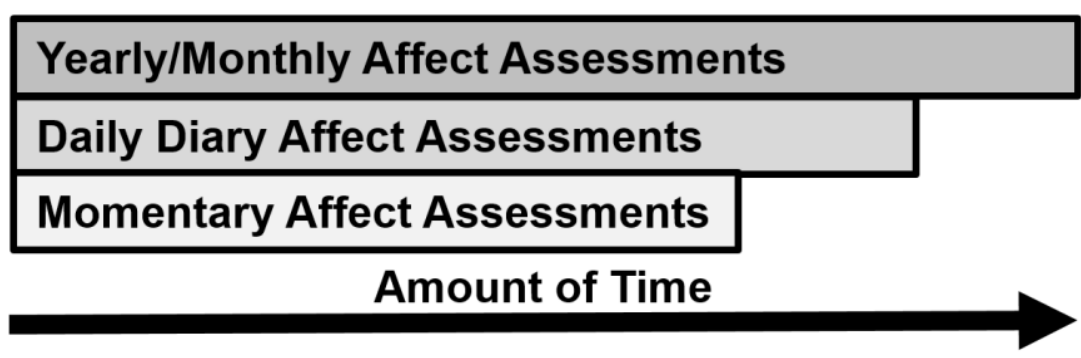

\section{Affective Dynamics and Aggression}

Across the temporal spectrum, variability in affect has been reliably linked to greater aggressive behavior.

Long-term studies of affect variability. Most aggression studies have examined long-term affect variability's relationship with aggressive behavior. Such investigations reliably reported correlations between greater long-term affective instability and greater aggression. For instance, trait affect dysregulation was linked to greater aggressive behavior (Miles et al., 2015). Individuals with greater affect instability 
were more aggressive than their more stable counterparts (Koenigsberg et al., 2001). Longitudinal studies of children and adolescents that spanned months and years demonstrated a robust association between dysregulated affect and greater aggression (Röll, Koglin, \& Petermann, 2012). Broad patterns of instability in affective experiences are thus well-linked to heightened aggressive tendencies.

\section{Daily diary and momentary assessment studies of affect variability. Other}

studies have examined the relationship between day-to-day affect variability and aggression. For example, variability in day-to-day levels of negative affect are linked to greater intimate partner violence (McNulty \& Hellmuth, 2008). Within-participant variability in daily diary reports of social pain were associated with greater aggression (DeWall, Lambert, Pond, Kashdan, \& Fincham, 2012; Kashdan et al., 2013). Using ecological momentary assessments over 28 days, parent-reported variability in a child's affect from day-to-day was associated with greater past aggression perpetrated by that child (Rosen \& Factor, 2015). Momentary variability in anxiety was associated with greater variability in momentary hostile aggression (Edmondson et al., 2013). Among individuals with pathological levels of borderline personality disorder and narcissism traits, momentary within-participant fluctuations in negative affect predicted greater momentary aggression (Scott et al., 2017; Wright et al., 2017). Across these sources of evidence, there is ample reason to expect that greater affective variability is linked to greater aggression.

\section{Gaps in the Literature}

The prevailing explanation for the link between affect instability and aggression is that it reflects a broader self-regulatory failure to inhibit situationally-induced and 
transient aversive affective states that then elicit an aggressive response (Denson, Capper, Oaten, Friese, \& Schofield, 2011; Denson, DeWall, \& Finkel, 2012; Finkel et al., 2012). However, this explanation evinces the pronounced and excessive focus of the aggression literature on negative affect, largely ignoring the role of positive affect. A growing literature has shown that positive affective states also play a robust role in motivating aggression (Chester, 2017). Indeed, aggression is linked not only to momentary pleasure and reward during the act (Chester \& DeWall, 2016) but is also motivated, in part, by the search for such positive affect (Chester \& DeWall, 2017). These links to positive affect are consequential as meta-analytic assessments show that dispositional pleasure experienced during aggression is one of the best predictors of antisocial and aggressive acts, with stronger effects than negative affect (Hyatt, Zeichner, \& Miller, 2019; Thielmann, Spadaro, \& Balliet, in press). The research literature has largely neglected to examine the role of positive affective states in relation to aggression and based on the meta-analytic evidence, we expect that it will exert effects on aggression even stronger than those of negative affect.

The literature on such affective dynamics has examined a wide array of timespans, yet it is largely missing investigations that assess momentary affect as it specifically precedes, co-occurs alongside, and occurs after an aggression incident. Such granularity is necessary to examine whether the link between affect instability and aggression is observed across all timespans or differs at moments immediately surrounding each aggressive act. Yet how should researchers examine these momentary affective dynamics surrounding aggression across both negative and positive valences? 


\section{Affective Dynamics: Flux, Pulse, and Spin}

Advances in quantifying and statistically modeling affective variability now allow researchers to distill complex affective dynamics into several informative indices. Notable among these indices are flux, pulse, and spin — which were originally introduced as metrics of variability in social behavior over time (Moskowitz \& Zuroff, 2004). Later, these metrics were translated to the affective domain (Kuppens, Van Mechelen, Nezlek, Dossche, \& Timmermans, 2007). Affective space can be accurately represented by placing negative and positive affect as orthogonal axes of a twodimensional grid (Tellegen et al., 1999; c.f. Barrett \& Bliss-Moreau, 2009). Flux, pulse, and spin represent different aspects of within-person variability in such two-dimensional affective spaces (Kuppens et al., 2007).

Flux refers to within-person variability in the intensity of one dimension of affective space (e.g., negatively-valenced affect). A 'high flux in negative affect' individual does not consistently feel one level of negative affect intensity (e.g., very intense negative affect). Instead, their experience of negative affect fluctuates wildly between very intense and hardly-noticeable levels. Such flux in one affect dimension (negative affect) does not inherently lead to any conclusions about the other dimension (positive affect).

Pulse refers to the same within-person variability of the intensity of affect, yet this metric aggregates across both dimensions of affect space (e.g., both negativelyvalenced and positively-valenced affect). A 'high pulse' person experiences dramatic shifts in general affect, such that sometimes they experience very little affect and other times they experience very intense affect. Whereas flux and pulse refer to the intensity 
of affective states, affect spin ignores intensity and focuses on changes in valence-type. More specifically, spin refers to variability in the combined valence of aggression-related affect (e.g., shifting from an affective state of greater negative valence and less positive affect to a blended affective state with greater levels of both negative and positive affect), irrespective of intensity. A 'high spin' person experiences large-scale changes in the 'flavor' of affect they experience, such that sometimes they experience overwhelmingly-negative affect and other times they experience overwhelminglypositive affect, with blended, interstitial affect states in between. These states may be very intense, have little intensity, or even fluctuate wildly in intensity. Pulse and spin can then be combined to better understand a given participant's within-person variability. Hypothetical examples of individuals with various combinations high and low in pulse and spin are provided in Figure 2. 
Figure 2. Hypothetical data depictions of the within-participant variability captured by high and low degrees of affect pulse and spin measured before [T1], during [T2], and after [T3] aggression. The circle in each panel represents the possible space for datapoints to exist in.

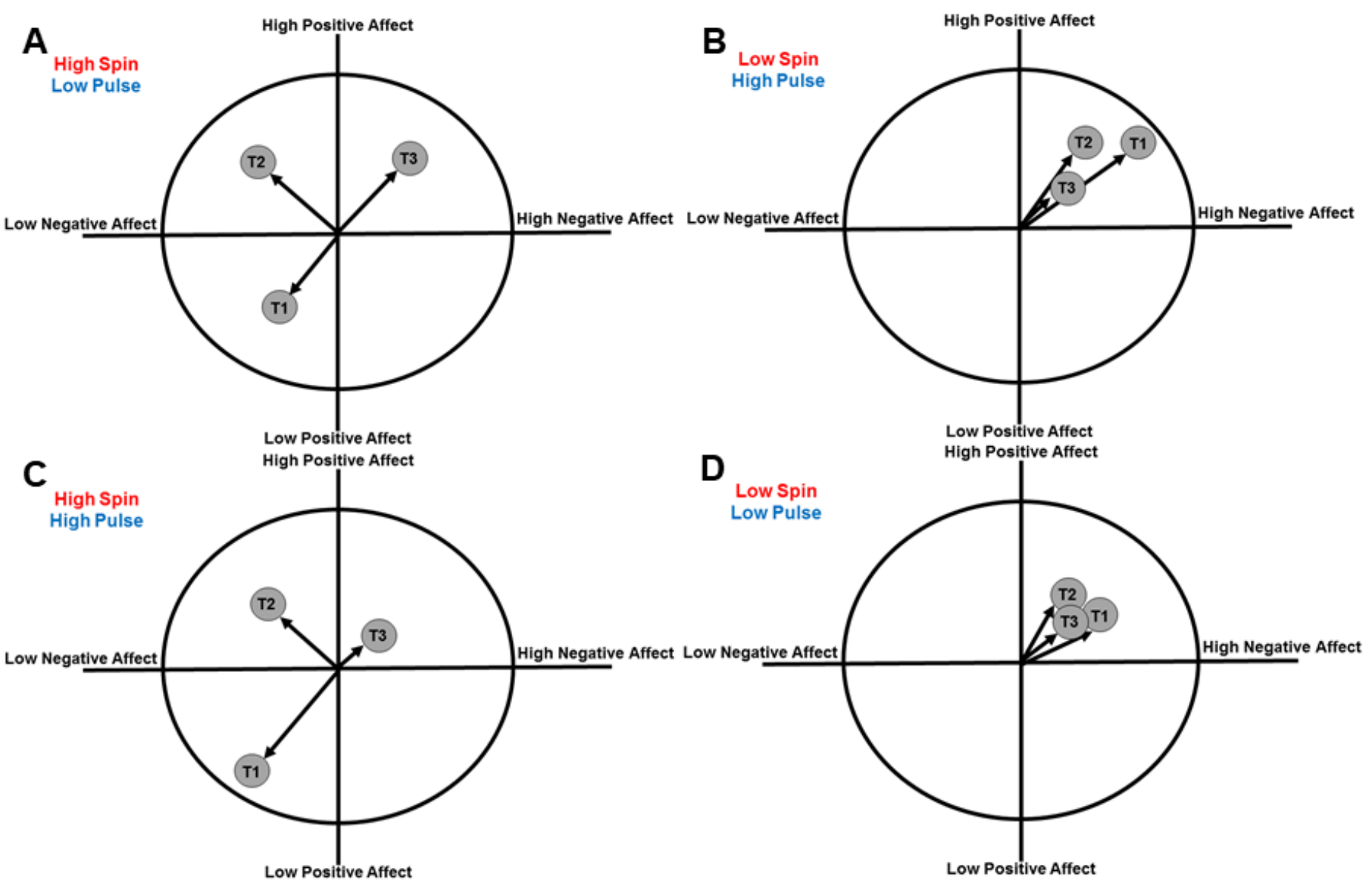

By using these indices to quantify within-participant variability in the affective states that occur before, during, and after aggression, we will be able to test predictions that will fill the current gaps in the literature on the dynamic affective bases of aggression.

\section{Present Research}

To test a series of predictions regarding the link between affect instability and 
greater aggression in the momentary affect that occurred surrounding aggression, we re-analyzed data from eight existing datasets. Given the established finding that instability in affective states are linked to greater aggression (DeWall et al., 2012; Finkel et al., 2012; Kashdan et al., 2013), we expected that each index of affect instability would be positively associated with aggressive behavior. Our preregistered predictions were that aggressive behavior and traits would be:

1. positively associated with greater flux ${ }^{1}$ in negative aggression-related affect.

2. positively associated with greater flux ${ }^{2}$ in positive aggression-related affect.

3. positively associated with greater spin in aggression-related affect.

No explicit predictions were made for affect pulse, but a positive association between pulse and aggression is a logical consequence of hypotheses 1 and 2 . We also preregistered that associations between flux in positive affect and aggression would be stronger than associations with flux in negative affect, given meta-analytic evidence that positive affect exhibits stronger effects on antisocial and aggressive behavior (Hyatt et al., 2019; Thielmann et al., in press). Deviating from our preregistration plan, we did not test our preregistered predictions regarding the effect of experimentally-induced provocation on affective pulse and spin, as these were beyond the scope of the present research, which focused more on aggression than provocation.

\section{Statistical Power Statement}

The average effect size for aggression studies suggests that samples of 130 or

\footnotetext{
1 This was incorrectly written as 'pulse' in our preregistration. The innocence of this error is proven by the fact that 'pulse' cannot be used in reference to a specific form of affect (i.e., negative or positive affect) as it only applies across both dimensions of affect.
} 
more participants have at least $80 \%$ power to detect main effects of this magnitude or larger ( $r=.24$; Richard, Bond, \& Stokes-Zoota, 2003). A priori power analyses were not used to determine the sample sizes in any of the eight studies, though they all surpass this sample size threshold and our meta-analytic estimates dramatically surpass this threshold.

\section{Open Science Statement}

All data files needed to reproduce these results and code to compute the affect indices can be publicly-accessed here: https://osf.io/v7k4z/files. Our preregistration plan is available here: https://osf.io/s93ju/register/5c08457ed283380029cf73bf. We deviated from this plan by basing our inferences on the results of internal meta-analyses and exploratory piecewise growth models that aggregated across all eight studies, instead of interpreting individual coefficients from each study. This deviation was motivated by the desire to base our inferences from a single, better-powered estimate, than by attempting to interpret eight separate coefficients for each effect.

\section{Methods}

\section{Ethics Statement}

All research procedures were approved by the appropriate research ethics committee.

\section{Overview}

Datasets from eight existing studies were re-analyzed to test our predictions. Each one of these studies included a validated measure of aggressive behavior and trait physical aggression, as well as reports of the negative and positive affect that participants experienced before, during, and after the aggression task. All datasets that 
were available to the first author and fit these criteria were re-analyzed for this purpose, excluding none.

\section{Participants}

Characteristics of participants (after excluding those who failed attention checks) from each study are presented in Table 1.

Table 1. Descriptive statistics of participants from each study.

\begin{tabular}{llllllll}
\hline Study & $N$ & Females & Males & Age $M$ & Age $S D$ & Age Range & Population \\
\hline 1 & 356 & 234 & 117 & 19.50 & 2.35 & $18-44$ & Undergraduates \\
2 & 317 & 136 & 181 & 33.15 & 11.18 & $18-85$ & MTurk Workers \\
3 & 348 & 233 & 115 & 19.15 & 3.05 & $18-47$ & Undergraduates \\
4 & 380 & 261 & 119 & 18.88 & 1.67 & $18-32$ & Undergraduates \\
5 & 153 & 74 & 78 & 33.44 & 10.31 & $20-66$ & MTurk Workers \\
6 & 162 & 116 & 42 & 19.08 & 1.84 & $18-35$ & Undergraduates \\
7 & 219 & 156 & 60 & 18.68 & 0.94 & $18-25$ & Undergraduates \\
8 & 238 & 176 & 62 & 19.35 & 1.81 & $18-36$ & Undergraduates \\
\hline
\end{tabular}

\section{Materials}

Aggressive behavior. Aggressive behavior was either measured with the Taylor Aggression Paradigm (TAP; Studies 6 and 7; Chester \& Lasko, 2019; Taylor, 1967) or the Voodoo Doll Aggression Task (VDAT; Studies 1-5 and 8; DeWall et al., 2013).

The Taylor Aggression Paradigm is framed as a competitive reaction time game played over the internet with a fictitious opponent. At the outset of each of the 17 (Study 6) or 25 (Study 7) trials of the task, participants set the volume (0 or $60-105$ decibels) and duration ( $0-5$ seconds) of an aversive noise blast that their opponent ostensibly 
heard if participants won the competition (i.e., pressed the button faster). A nonaggression option was also provided (coded as 0 ). The volume and duration settings were coded 0 (no volume, no duration) - 10 (highest volume, longest duration). The order of participant wins and losses were randomized and then held constant across all participants, except that they automatically lost any competition to which they did not respond quickly. Participants' opponents always selected the loudest and longest noise blast on the first trial in order to provoke participants.

The Voodoo Doll Aggression Task (VDAT) took the form of a virtual image of a doll that participants were told to imagine as a human target. Participants were then given an opportunity to symbolically harm that person by selecting the number of sharp pins to insert into the doll (from 0 to 51 pins). VDAT scores were computed by adding 1 to all raw scores and then applying a base 10 logarithmic transformation to this data, as doing so reduces issues with skewness and kurtosis (Chester \& Lasko, 2019).

Negative and positive affect. Negative and positive affective states were measured using the 3-item Negative Affect subscale ('I feel/felt: bad, angry, sad') and the 3-item Positive Affect subscale ('I feel/felt: good, happy, pleasant') of the larger Need Threat Scale (Riva, Wirth, \& Williams, 2011; Van Beest \& Williams, 2006; Williams, 2009). These items were adapted to the Need Threat Scale from the Scale of Positive and Negative Experience (Diener, 2013). Participants rated their experience of each affective state along a 1 (strongly disagree) to 5 (strongly agree).

Trait physical aggression. Trait physical aggression was assessed with either the 9-item Physical Aggression subscale of the 29-item Buss-Perry Aggression Questionnaire (BPAQ; Buss \& Perry, 1992) or the 3-item Physical Aggression subscale 
of the 12-item Brief Aggression Questionnaire (BAQ; Webster et al., 2014). Participants responded to self-descriptive items along a 1 (strongly disagree) to 7 (strongly agree).

\section{Procedure}

Study 1. In this online study ${ }^{2}$, participants were randomly assigned to be either socially rejected $(N=177)$ or accepted $(N=179)$ via the Cyberball paradigm (version 4.0; Williams, Cheung, \& Choi, 2000; Williams, Yeager, Cheung, \& Choi, 2012). In this paradigm, participants connected to what were ostensibly two same-sex undergraduate students who they toss a virtual ball with, receiving it an equal number of times. In the acceptance condition, this equal ball receipt continues throughout the task, whereas in the rejection condition, participants stop receiving the ball from their partners after receiving the ball three times. After the Cyberball task, participants reported their negative and positive affect via the Need Threat Scale and then completed the Voodoo Doll Aggression Task, with one of their Cyberball partners as the target. Finally, participants completed a battery of questionnaires that included retrospective reports of negative and positive affect during the Voodoo Doll Aggression Task and their current affect after this task. Embedded in the battery of questionnaires were two attention check items, which excluded 32 participants from an original, larger sample. Participants were then debriefed via an online webpage.

\footnotetext{
${ }^{2}$ Aggressive behavior, trait physical aggression, affect, and demographic data from this study has been published elsewhere (Chester \& Dzierzewski, in press - Study 1; Chester, DeWall, \& Enjaian, 2019 Study 7), though never analyzed in relation to affect flux, pulse, or spin.
} 
Study 2. In this online study ${ }^{3}$, participants reported their negative and positive affect via the Need Threat Scale and then completed the Voodoo Doll Aggression Task, with a 'person that you are very angry towards' as the target. Finally, participants completed a battery of questionnaires that included retrospective reports of negative and positive affect during the Voodoo Doll Aggression Task and their current affect after this task. Embedded in the battery of questionnaires was one attention check item, which excluded 154 participants from an original, larger sample. Participants were then debriefed via an online webpage.

Study 3. In this online study ${ }^{4}$, participants reported their negative and positive affect via the Need Threat Scale and then completed the Voodoo Doll Aggression Task, with a 'person that you are very angry towards' as the target. Finally, participants completed a battery of questionnaires that included retrospective reports of negative and positive affect during the Voodoo Doll Aggression Task and their current affect after this task. Embedded in the battery of questionnaires was one attention check item, which excluded 31 participants from an original, larger sample. Participants were then directed to a second wave of the study approximately two weeks later, which debriefed them via an online webpage.

Study 4. In this online study, participants were randomly assigned to be either

\footnotetext{
${ }^{3}$ Aggressive behavior, trait physical aggression, affect, and demographic data from this study has been published elsewhere (Chester \& Dzierzewski, in press - Study 2), though never analyzed in relation to affect flux, pulse, or spin.

${ }^{4}$ Aggressive behavior, trait physical aggression, affect, and demographic data from this study has been published elsewhere (Chester \& Dzierzewski, in press - Study 3), though never analyzed in relation to affect flux, pulse, or spin.
} 
socially rejected $(N=191)$ or accepted $(N=189)$ via the Cyberball paradigm. After the Cyberball task, participants reported their negative and positive affect via the Need Threat Scale and then completed the Voodoo Doll Aggression Task, with one of their Cyberball partners as the target. Finally, participants completed a battery of questionnaires that included retrospective reports of negative and positive affect during the Voodoo Doll Aggression Task and their current affect after this task. Participants were then debriefed via an online webpage.

Study 5. In this online study ${ }^{5}$, participants were randomly assigned to be either provoked $(N=73)$ or unprovoked $(N=79)$ via the essay evaluation paradigm (as in Chester \& DeWall, 2017). In this task, participants wrote a brief essay, which was ostensibly exchanged with another same-sex undergraduate student. Participants either received a good numerical score and positive written feedback (unprovoked condition) or a poor numerical score and negative written feedback (provoked condition). After this essay evaluation task, participants reported their negative and positive affect via the Need Threat Scale and then completed the Voodoo Doll Aggression Task, with one of their Cyberball partners as the target. Finally, participants completed a battery of questionnaires that included retrospective reports of negative and positive affect during the Voodoo Doll Aggression Task and their current affect after this task. Embedded in this battery of questionnaires was one attention check item, which excluded three participants from an original, larger sample. Participants were then debriefed via an

\footnotetext{
${ }^{5}$ Aggressive behavior, trait physical aggression, affect, and demographic data from this study has been published elsewhere (Chester \& DeWall, 2017 - Study 5; Chester et al., 2019 - Study 5), though never analyzed in relation to affect flux, pulse, or spin.
} 
online webpage.

Study 6. This laboratory study ${ }^{6}$ was part of a larger project on caffeine's influence on aggression. By random assignment, participants either consumed a capsule containing $100 \mathrm{mg}$ of caffeine $(N=54)$, consumed a placebo capsule of corn starch $(N=50)$, or did not consume a capsule $(N=58)$. Participants then watched nature videos for 30 minutes and reported their negative and positive affect via the Need Threat Scale. Participants were then experimentally provoked by having them try to complete a set of difficult and impossible anagrams. Participants then completed the Taylor Aggression Paradigm (TAP) against a same-sex undergraduate student. Then, participants retrospectively reported their affective state during aggression and then again reported their current post-aggression negative and positive affect. After completing other questionnaires, participants were debriefed by an experimenter.

Study 7. In this laboratory study ${ }^{7}$, participants were randomly-assigned to be accepted $(N=121)$ or rejected $(N=98)$ via the Cyberball paradigm, ostensibly with two same-sex undergraduates. Participants then reported their current negative and positive affect via the Need Threat Scale and completed the Taylor Aggression Paradigm against one of their Cyberball partners. Then, participants retrospectively reported their affective state during aggression and then again reported their current post-aggression

\footnotetext{
${ }^{6}$ Aggressive behavior, trait physical aggression, affect, and demographic data from this study has been published elsewhere (Chester et al., 2019 - Study 1), though never analyzed in relation to affect flux, pulse, or spin.

${ }^{7}$ Aggressive behavior, trait physical aggression, affect, and demographic data from this study has been published elsewhere (Chester \& DeWall, 2017 - Study 2), though never analyzed in relation to affect flux, pulse, or spin.
} 
negative and positive affect. After completing other questionnaires, participants were debriefed by an experimenter.

Study 8. This laboratory study ${ }^{8}$ was part of a broader project on self-regulatory fatigue and aggression. Participants wrote an essay and were randomly-assigned such that they could not use the letters $X$ or $Z$ (control condition; $N=114$ ) or $A$ or $N$ (fatigue condition; $N$ = 124; Mead, Baumeister, Gino, Schweitzer, \& Ariely, 2009). After doing so, participants reported their current negative and positive affect via the Need Threat Scale and completed the Voodoo Doll Aggression Task, with a 'person that you are very angry towards' as the target. Then, participants retrospectively reported their affective state during aggression and then again reported their current post-aggression negative and positive affect. After completing other questionnaires, participants were debriefed by an experimenter.

\section{Computation of Affective Indices}

Dynamic affective indices of flux, pulse, and spin were computed as in Kuppens and colleagues (2007).

Flux. Flux variables for both negative and positive affect were created for each participant by computing the within-participant standard deviation of each affect-type's three timepoints (i.e., before, during, after aggression).

Pulse. A pulse variable was computed for each participant in two steps. First, we compute an 'affect distance' value for each timepoint (i.e., before, during, after

\footnotetext{
${ }^{8}$ Aggressive behavior, trait physical aggression, affect, and demographic data from this study has been published elsewhere (Chester et al., 2019 - Study 8), though never analyzed in relation to affect flux, pulse, or spin.
} 
aggression) by squaring, adding, and then square-rooting the negative and positive affect values for each given timepoint. Second, pulse was computed as the withinparticipant standard deviation of those three 'affect distance' values.

Spin. A spin variable was computed for each participant in four steps. First, six 'unit vectors' were computed for each affect-type and each timepoint (e.g., PreAggression Negative Affect) by dividing each participant's mean value for this variable by the corresponding 'affective distance' variable described in the previous section. Second, we computed an 'affect vector' variable for each affect-type by summing the three 'unit vectors' of that affect type (e.g., summing the Pre-Aggression Positive Affect, During-Aggression Positive Affect, and Post-Aggression Positive Affect unit vectors to create a 'Positive Affect Vector'). Third, we created an 'affect variance' variable for each participant by squaring and adding the two 'affect vectors' to each other and then dividing this value by the number if timepoints (i.e., three). Fourth, affect spin was computed as the natural logarithm of the 'affect variance' index, which was then multiplied by -2 and square-rooted.

\section{Results}

\section{Descriptive Statistics}

Descriptive statistics for each affect, aggressive behavior, and trait physical aggression measure from each study is provided in Table 2. 
Table 2. Descriptive statistics for key measures of Studies 1-8. aRated along a longer, 7point Likert scale.

\begin{tabular}{ccccccccc}
\hline Statistic & Study 1 & Study 2 & Study 3 & Study 4 & Study 5 & Study 6 & Study 7 & Study 8 \\
\multicolumn{7}{c}{ Brief/Buss-Perry } & Aggression & Questionnaire (Physical Aggression subscale) \\
$M$ & 3.24 & 3.50 & 2.47 & 3.29 & 3.48 & 2.58 & 2.93 & 2.97 \\
$S D$ & 1.74 & 1.56 & 1.02 & 1.70 & 1.82 & 1.48 & 1.79 & 1.54 \\
$\alpha$ & .82 & .89 & .78 & .81 & .83 & .79 & .84 & .72
\end{tabular}

Need Threat Scale - Negative Affect (Pre-Aggression)

$\begin{array}{lllllllll}M & 1.59 & 2.06 & 1.77 & 1.74 & 2.88^{\mathrm{a}} & 1.49 & 1.60 & 1.47 \\ S D & 0.78 & 1.16 & 0.81 & 0.97 & 1.67^{\mathrm{a}} & 0.61 & 0.71 & 0.70 \\ \alpha & .82 & .89 & .77 & .90 & .87 & .71 & .77 & .82\end{array}$

Need Threat Scale - Positive Affect (Pre-Aggression)

$\begin{array}{lllllllll}M & 3.05 & 3.87 & 3.42 & 3.00 & 4.70^{\mathrm{a}} & 3.42 & 3.47 & 3.67 \\ S D & 1.04 & 0.90 & 0.87 & 1.07 & 1.71^{\mathrm{a}} & 0.86 & 0.93 & 0.84 \\ \alpha & .90 & .85 & .87 & .91 & .92 & .87 & .90 & .85\end{array}$

Need Threat Scale - Negative Affect (During Aggression)

$\begin{array}{lllllllll}M & 2.29 & 3.49 & 2.66 & 2.04 & 3.65^{\mathrm{a}} & 2.01 & 2.21 & 2.30 \\ S D & 1.51 & 1.74 & 1.50 & 0.99 & 1.67^{\mathrm{a}} & 0.88 & 0.95 & 1.00 \\ \alpha & .79 & .80 & .74 & .74 & .81 & .62 & .67 & .53\end{array}$

Need Threat Scale - Positive Affect (During Aggression)

$\begin{array}{lllllllll}M & 2.53 & 4.27 & 2.79 & 2.00 & 3.63^{\mathrm{a}} & 2.40 & 2.58 & 2.24 \\ S D & 1.72 & 1.89 & 1.85 & 1.07 & 1.98^{\mathrm{a}} & 1.15 & 1.04 & 1.22\end{array}$


$\begin{array}{lllllllll}\alpha & .91 & .92 & .92 & .91 & .95 & .85 & .80 & .84\end{array}$

Need Threat Scale - Negative Affect (Post-Aggression)

$\begin{array}{lllllllll}M & 1.76 & 2.28 & 1.93 & 1.71 & 2.59^{\mathrm{a}} & 1.68 & 1.77 & 1.58 \\ S D & 0.94 & 1.18 & 0.90 & 0.87 & 1.59^{\mathrm{a}} & 0.77 & 0.77 & 0.77 \\ \alpha & .84 & .87 & .79 & .83 & .86 & .68 & .71 & .78\end{array}$

Need Threat Scale - Positive Affect (Post-Aggression)

$\begin{array}{lllllllll}M & 2.54 & 3.63 & 2.92 & 2.56 & 4.95^{\mathrm{a}} & 3.03 & 3.30 & 3.56 \\ S D & 1.16 & 1.01 & 1.14 & 1.16 & 1.61^{\mathrm{a}} & 0.96 & 1.00 & 0.94 \\ \alpha & .91 & .85 & .92 & .91 & .93 & .85 & .86 & .88\end{array}$

Taylor Aggression Paradigm

$\begin{array}{llllllll}M & - & - & - & - & - & 3.80 & 5.09 \\ S D & - & - & - & - & - & 2.25 & 1.97 \\ \alpha & - & - & - & - & - & .98 & .96\end{array}$

Voodoo Doll Aggression Task

$\begin{array}{lllllllll}M & 0.52 & 1.04 & 0.79 & 0.45 & 0.54 & - & - & 0.63 \\ S D & 0.61 & 0.66 & 0.64 & 0.57 & 0.65 & - & - & 0.64\end{array}$

\section{Exploratory Principal Component Analyses}

To ensure that the Need Threat Scale's affect subscales reflected the intended Negative Affect and Positive Affect components, we conducted an exploratory principal components analysis using varimax rotation on raw, item-level data from all participants. At each timepoint (before, during, and after aggression), the six NTS items clearly loaded onto two distinct Negative Affect and Positive Affect subscales, each of which exhibited excellent internal consistency in the aggregate (see Supplemental Tables 1 
and 2).

\section{Correlations with Aggressive Behavior}

Internal meta-analyses. Internal, random-effects meta-analyses using restricted maximum likelihood (REML) estimation were performed using JASP v.9.0 across each study's zero-order correlations between aggressive behavior and the flux, pulse, and spin indices that were computed across all three timepoints. Counter to our predictions, aggressive behavior was not associated with flux in negative affect, pulse, or spin, but was associated with less flux in positive affect (Table 3; Figure 3). Whether participants were experimentally provoked prior to the aggression task did not moderate the link between flux in positive affect and aggressive behavior, $F(1,2084)=3.19, p=.074$. Meta-analytic results throughout this manuscript did not systematically differ by whether the study was conducted online versus in-lab or whether the sample was comprised of undergraduates or Mechanical Turk workers.

Table 3. Results of internal meta-analyses for the effect of aggressive behavior on flux, pulse, and spin.

\begin{tabular}{lcccccc}
\hline Affect Variable & $r(95 \% C l)$ & $S E$ & $Z$ & $p$ & $Q(7)$ & $p$ \\
\hline Flux - Negative & $.05(-.06, .15)$ & 0.06 & 0.83 & .409 & 46.46 & $<.001$ \\
Flux - Positive & $-.14(-.20,-.09)$ & 0.03 & -5.37 & $<.001$ & 10.55 & .159 \\
Pulse & $-.06(-.13, .00)$ & 0.03 & -1.97 & .049 & 15.18 & .034 \\
Spin & $-.09(-.17, .00)$ & 0.04 & -2.05 & .040 & 25.30 & $<.001$ \\
& & & & & &
\end{tabular}

Figure 3. Forest plot of aggressive behavior effects on flux in positive affect from all eight studies. Numbers on the left represent the study of origin for each effect and values on the right represent individual effect sizes and their associated 95\% 
confidence intervals.

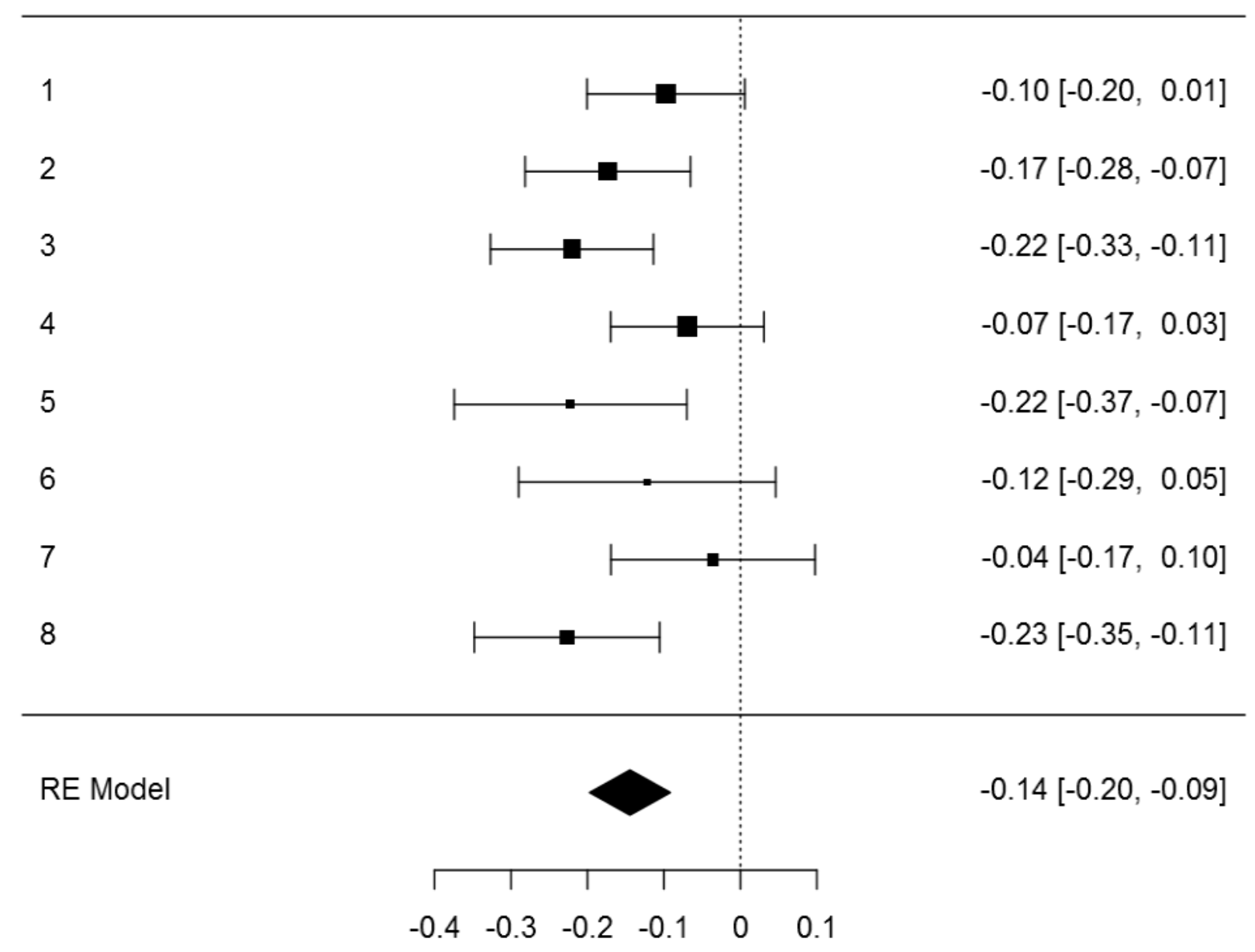

We then probed this flux effect by conducting a separate meta-analysis that examined the effect of aggressive behavior on mean positive affect at each individual timepoint. The negative association between aggressive behavior and flux in positive affect was driven by variability in positive affect during the aggression task (Table 4). Table 4. Results of internal meta-analyses for the effect of aggressive behavior on positive affect before, during, and after aggression.

\begin{tabular}{lcccccc}
\hline Timepoint & $r(95 \% C l)$ & $S E$ & $Z$ & $p$ & $Q(7)$ & $p$ \\
\hline Before Aggression & $-.06(-.14, .03)$ & 0.04 & -1.30 & .192 & 27.85 & $<.001$
\end{tabular}




$\begin{array}{lllllll}\text { During Aggression } & .15(.03, .27) & 0.06 & 2.45 & .014 & 57.79 & <.001 \\ \text { After Aggression } & -.01(-.10, .09) & 0.05 & -0.12 & .901 & 39.27 & <.001\end{array}$

Exploratory piecewise growth analyses. To further examine the trajectories of positive affect between the three timepoints, we employed multilevel piecewise linear growth modeling (Chou, Yang, Pentz, \& Hser, 2004; Liu, Liu, Li, \& Zhao, 2015) via the Ime4 and ImerTest packages in R statistical software. This piecewise approach allowed us to separately examine trajectories of positive affect as they occurred before and after the aggression task. To conduct this model, we combined participants from all eight studies after standardizing their positive affect and aggressive behavior within each study (as recommended for such integrative data analyses; Curran \& Hussong, 2009). This model nested participants within study and then modeled random intercepts and two random slopes that represented the pre-aggression and post-aggression trajectories of aggression-related positive affect. This first level was represented by the following equation, where subscript $t$ represents each timepoint and subscript $i$ represents each participant:

Affect $_{t i}=\pi_{0 i}+\pi_{1 i}($ Pre-Aggression Slope $)+\pi_{2 i}($ Post-Aggression Slope $)+e_{t i}$

We then modeled the fixed effects of aggressive behavior and its interaction with each slope variable at level 2 of the model:

\section{Affect ${ }_{i}=\beta_{0}+\beta_{1}($ Aggression $)+\beta_{2}($ Aggression $\times$ Pre-Aggression Slope $)+$ $\beta_{3}($ Aggression x Post-Aggression Slope $)+r_{i}$}

The model revealed that participants exhibited initial declines in positive affect as they completed the aggression task and then subsequently returned to baseline and that these trajectories were moderated by how aggressive participants were on the task 
(Table 5).

Table 5. Results of the piecewise growth model for change in positive affect (nested by study) as moderated by aggressive behavior, with separate slopes for pre-aggression (Slope 1) and post-aggression (Slope 2) timeframes.

\begin{tabular}{lccccc}
\hline Effect & $B$ & $S E$ & $t$ & $d f$ & $p$ \\
\hline Intercept & 3.47 & 0.03 & 113.95 & 2,304 & $<.001$ \\
Slope 1 & -0.76 & 0.05 & -16.14 & 2,332 & $<.001$ \\
Slope 2 & 0.40 & 0.04 & 9.18 & 2,322 & $<.001$ \\
Aggressive Behavior & 0.00 & 0.01 & -0.09 & 2,208 & .928 \\
Slope 1 x Aggressive Behavior & 0.10 & 0.02 & 4.05 & 3,356 & $<.001$ \\
Slope 2 x Aggressive Behavior & -0.05 & 0.02 & -2.39 & 2,599 & .017 \\
\hline
\end{tabular}

These interactive effects between aggressive behavior and each slope were probed using an online utility (http://www.quantpsy.org/interact/hlm2.htm; case 3; Preacher, Curran, \& Bauer, 2006). The simple slopes revealed that positive affect declined during the aggression task and then increased afterwards, but that these effects were diminished among individuals who exhibited greater aggressive behavior (Figure 4; Table 6). 
Figure 4. Simple slopes of positive affect across timepoints of all eight studies, at relative levels of aggressive behavior. Central intercepts are offset as slope estimates were calculated from two separate multilevel models, one for each pair of timepoints.

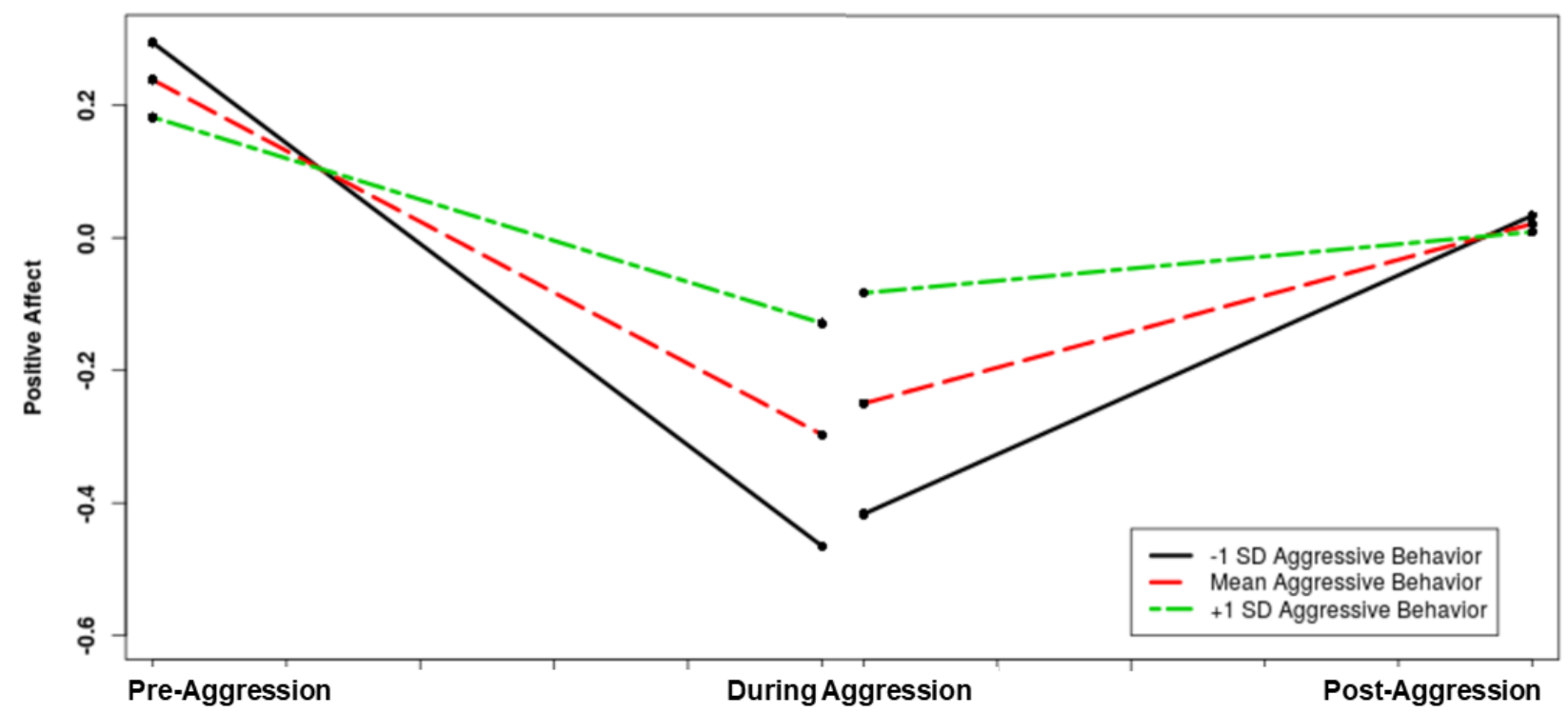

Table 6. Simple slope statistics of positive affect across timepoints of all eight studies, at relative levels of aggressive behavior.

\begin{tabular}{lcccccccc}
\hline & \multicolumn{3}{c}{ Pre -> During } & Aggression & \multicolumn{5}{c}{ During $->$ Post Aggression } \\
\hline Aggression & $B$ & $S E$ & $t$ & $p$ & $B$ & $S E$ & $t$ & $p$ \\
\hline$-1 S D$ & -0.76 & 0.04 & -17.76 & $<.001$ & 0.45 & 0.04 & 11.45 & $<.001$ \\
Mean & -0.54 & 0.03 & -17.56 & $<.001$ & 0.27 & 0.03 & 9.72 & $<.001$ \\
$+1 S D$ & -0.31 & 0.04 & -7.28 & $<.001$ & 0.09 & 0.04 & 2.35 & .019 \\
\hline
\end{tabular}

\section{Correlations with Trait Physical Aggression}

Internal meta-analyses. As with aggressive behavior, we observed that trait physical aggression was not associated with flux in negative affect or pulse, and was negatively associated with flux in positive affect (Table 7; Figure 5). Whether participants were experimentally provoked prior to the aggression task did not moderate 
the link between flux in positive affect and trait aggression, $F(1,2112)=0.03, p=.859$. Trait physical aggression was also negatively associated with affect spin, but substantial heterogeneity undermined the likely validity of this effect.

Table 7. Results of internal meta-analyses for the effect of trait physical aggression on flux, pulse, and spin.

\begin{tabular}{lcccccc}
\hline Affect Variable & $r(95 \% C)$ & $S E$ & $Z$ & $p$ & $Q(7)$ & $p$ \\
\hline Flux - Negative & $-.02(-.10, .06)$ & 0.04 & -0.59 & .556 & 24.32 & .001 \\
Flux - Positive & $-.07(-.11,-.02)$ & 0.02 & -3.07 & .002 & 3.64 & .820 \\
Pulse & $.03(-.09, .14)$ & 0.06 & 0.43 & .669 & 61.58 & $<.001$ \\
Spin & $-.12(-.20,-.03)$ & 0.04 & -2.77 & .006 & 32.11 & $<.001$ \\
\hline
\end{tabular}


Figure 5. Forest plot of trait physical aggression effects on flux - positive scores from all eight studies. Numbers on the left represent the study of origin for each effect and values on the right represent individual effect sizes and their associated 95\% confidence intervals.

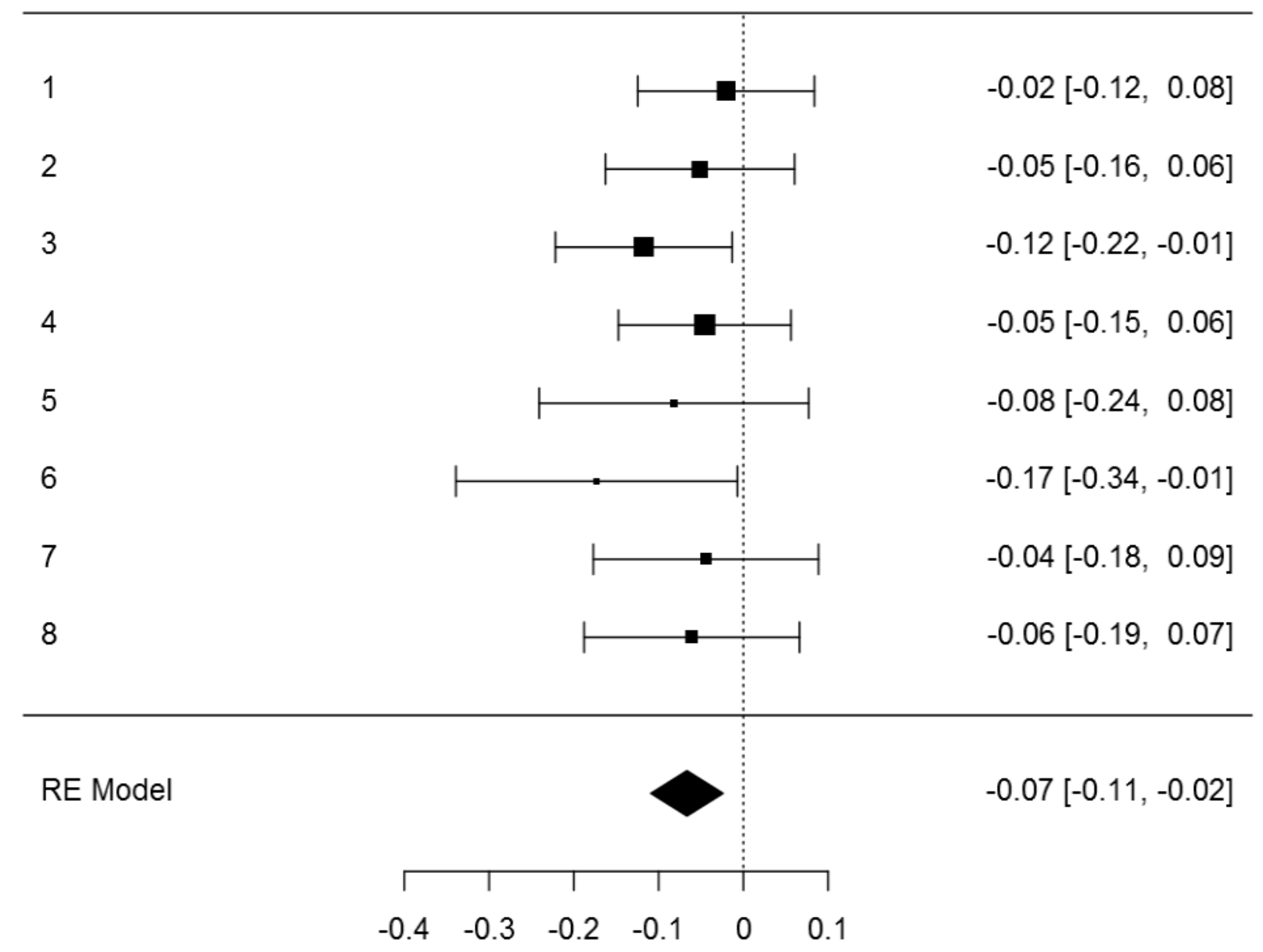

As with aggressive behavior, the observed association between trait physical aggression and flux in positive affect was driven by variability in state affect during the aggression task (Table 8). 
Table 8. Results of internal meta-analyses for the effect of trait physical aggression on positive affect before, during, and after aggression.

\begin{tabular}{lcccccc}
\hline Timepoint & $r(95 \% C l)$ & $S E$ & $Z$ & $p$ & $Q(7)$ & $p$ \\
\hline Before Aggression & $.04(-.05, .12)$ & 0.04 & 0.85 & .398 & 29.81 & $<.001$ \\
During Aggression & $.15(.03, .28)$ & 0.06 & 2.40 & .016 & 71.48 & $<.001$ \\
After Aggression & $.02(-.06, .11)$ & 0.04 & 0.53 & .593 & 30.75 & $<.001$ \\
\hline \multicolumn{7}{l}{ Exploratory piecewise growth analyses. We again employed exploratory }
\end{tabular}

piecewise growth models using the same parameters as the previous analysis, which revealed initial declines in positive affect with subsequent returns to baseline and that these trajectories were moderated by trait physical aggression (Table 9).

Table 9. Results of the piecewise growth model for change in positive affect (nested by study) as moderated by trait physical aggression, with separate slopes for preaggression (Slope 1) and post-aggression (Slope 2) timeframes.

\begin{tabular}{lccccc}
\hline Effect & $B$ & $S E$ & $t$ & $d f$ & $p$ \\
\hline Intercept & 3.48 & 0.05 & 70.03 & 2,730 & $<.001$ \\
Slope 1 & -1.14 & 0.07 & -14.72 & 2,906 & $<.001$ \\
Slope 2 & 0.69 & 0.07 & 9.49 & 2,756 & $<.001$ \\
Trait Aggression & 0.00 & 0.01 & -0.25 & 3,001 & .800 \\
Slope 1 x Trait Aggression & 0.15 & 0.02 & 7.19 & 3,309 & $<.001$ \\
Slope 2 x Trait Aggression & -0.11 & 0.02 & -5.52 & 3,069 & $<.001$
\end{tabular}

Probing these interactive effects showed again that positive affect declined during the aggression task and then increased afterwards, but that these effects were diminished among individuals with greater trait physical aggression (Figure 6; Table 10). 
Figure 6. Simple slopes of positive affect across timepoints of all eight studies, at relative levels of trait physical aggression. Central intercepts are offset as slope estimates were calculated from two separate multilevel models, one for each pair of timepoints.

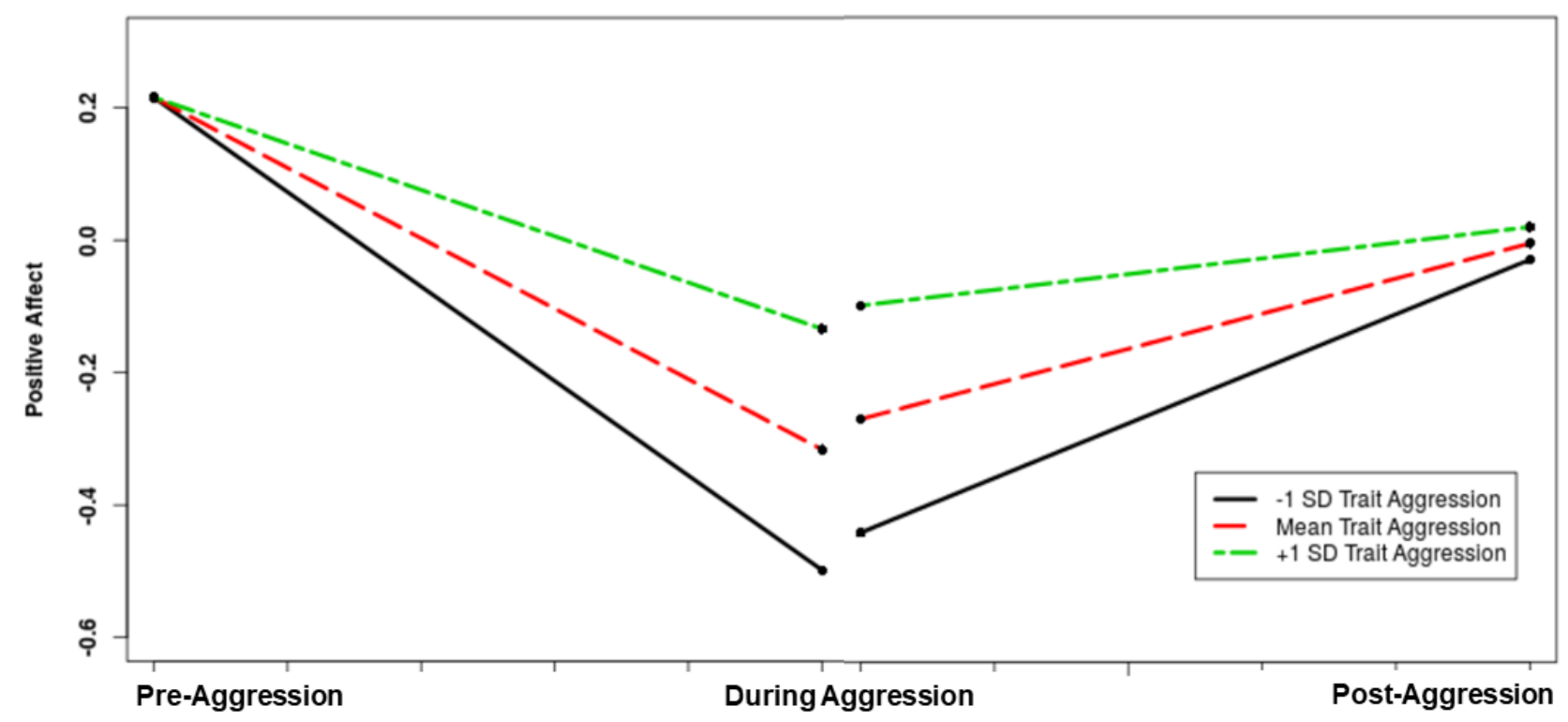

Table 10. Simple slope statistics of positive affect across timepoints of all eight studies, at relative levels of trait physical aggression.

\begin{tabular}{lcccccccc}
\hline & \multicolumn{3}{c}{ Pre -> During Aggression } & \multicolumn{5}{c}{ During $->$ Post Aggression } \\
\hline Trait Aggression & $B$ & $S E$ & $t$ & $p$ & $B$ & $S E$ & $t$ & $p$ \\
\hline$-1 S D$ & -0.71 & 0.04 & -16.76 & $<.001$ & 0.41 & 0.04 & 10.50 & $<.001$ \\
Mean & -0.53 & 0.04 & -17.49 & $<.001$ & 0.26 & 0.03 & 9.50 & $<.001$ \\
$+1 S D$ & -0.35 & 0.04 & -8.22 & $<.001$ & 0.12 & 0.04 & 3.03 & .003 \\
& & & & & & & &
\end{tabular}

\section{Discussion}

Affect changes dynamically over time and across situations. Such affective variability has long been studied as a proximal psychological basis for aggressive 
behavior. However, research is lacking into variability in the momentary affective states that directly precede, occur during, and follow a specific aggressive act. To fill this gap in the literature, we re-analyzed eight existing studies that included an aggression task alongside three assessments of affect surrounding the task. We quantified withinparticipant variability in the intensity of negative and positive affect as flux (for each affect-type) and pulse (across affect-types), and the variability in the combination of negative and positive valence as spin.

\section{The Utility of Flux, Pulse, and Spin}

Prior research in affective dynamics often relied upon daily diaries and ecological momentary assessments of affect, using multilevel modeling to investigate variability in these repeated assessments (e.g., Scott et al., 2017). Our approach that combined rapidly-assessed affect with dynamic affect indices suggests that this quantitative approach can reveal effects that are not observable using these other means. Further, our findings point to the utility of employing flux, pulse, and spin indices. These metrics identified specific aspects of the affective timecourse (e.g., positive affect experienced during aggression) that yielded valuable information when probed further. In this way, the indices of flux, pulse, and spin can be used to direct investigators towards the most promising aspects of dynamic affect data, saving valuable time and resources.

\section{A New Focus on Stability}

Across all eight studies and against our predictions, greater aggressive behavior was associated with less flux (i.e., less variability in the intensity) of positive affect surrounding aggression. Probing this effect further, we observed that this flux effect was driven by a relatively stable level of positive affect across all three timepoints, whereas 
less aggressive individuals exhibited a marked decrease in positive affect during the aggressive act. This finding advances the previous research literature linking aggression to unstable, volatile, reactive, and labile affect (e.g., Cohn, Zeichner, \& Seibert, 2008) by showing that affective stability can sometimes promote impulsive and antisocial behaviors. We also did not observe an association between aggression and flux in negative affect. This null association does not support the link between affect instability and aggression, and suggests that this effect may not hold at more granular temporal resolutions and that it may be specific to broader timeframes (e.g., daily diary studies).

Aggressive behavior and traits were unassociated with affect pulse and only weakly linked to less affect spin. Both pulse and spin effects were accompanied by substantial underlying heterogeneity among the eight studies. Because of the small size of the effects, the tepid levels of statistical significance, and their underlying heterogeneity, the robustness of these findings is uncertain. Whether they are a product of heterogeneity or not, they exist as a further lack of evidence for the association between affect instability and momentary aggression-related affect at the momentary level of an aggression event.

\section{A New Focus on Positive Affect}

Previous research has almost entirely focused on negative forms of affect in relation to aggression (e.g., anger; Wilkowski \& Robinson, 2010) and our findings suggest that aggression researchers should pay more attention to positive affective states. Several studies serve as notable exceptions, in which positive affect was repeatedly assessed across the duration of laboratory aggression paradigms alongside 
assessments of negative affect. In these studies, laboratory aggression was also linked to decreases in positive affect (Gilam, Abend, Shani, Ben-Zion, \& Hendler, 2019; Gilam et al., 2015). As such, our findings thus replicate and extend this prior work, though more research on this topic is needed.

\section{Reinforcement Model}

More dispositionally-aggressive individuals exhibited relatively stable and elevated positive affect across the aggression task. These findings suggest that aggression's link with stability in aggression-related positive affect extends beyond the immediate aggressive act to individuals' broader behavior patterns. Indeed, our results lend preliminary support to a reinforcement model of aggression, in which greater experiences of positive affect and reward serve to establish and reinforce aggressive acts (Chester, Lynam, Milich, \& DeWall, 2018). The affective mechanisms revealed in the present research may serve as proximate pathways underlying why some individuals are ultimately more dispositionally aggressive than others.

Unexpectedly, participants did not evince absolute increases in positive affect during the aggression task, as such affect levels decreased from the initial assessment across the relative levels of trait aggression. However, we only probed our interaction up to one standard deviation from the mean. Physical aggression is mostly perpetrated by a small fraction of the populace (Anderson \& Bushman, 2002) and therefore such absolute increases in aggression-related positive affect were likely observed at these more extreme tails of the trait aggression distribution. Further, absolute increases in positive affect are not required for reinforcement processes to occur. Relatively higher levels of positive affect from one individual to another, even if they represent absolute 
within-person decreases from a previous timepoint, can facilitate reinforcement learning (Capaldi, 1966). More research is needed to examine whether reinforcement mechanisms are reflected in our pattern of results and their potential contributions to real-world violence.

\section{Limitations and Future Directions}

Arousal. According to core affect and affect circumplex models of affect, arousal is a key dimension of affective states (Barrett \& Bliss-Moreau, 2009; Russell, 2003). We did not effectively measure and therefore we did not model arousal across these studies. Our affect measures included items that captured high arousal (angry, happy), low arousal (sad), or were without clear arousal levels (bad, good, pleasant). Future research will benefit from measuring and modeling the arousal dynamics associated with greater aggressive behavior, as arousal is a long-standing factor in studying aggression (Zillmann, Katcher, \& Milavsky, 1972).

Generalizability. Our participants were mostly undergraduate students and the remaining were Mechanical Turk workers. Although many of the undergraduate samples were ethnically- and racially-diverse, it is unlikely that undergraduate students' experience of aggression is widely generalizable. Future research recruiting clinicallyand forensically-violent individuals, as well as those from a diverse array of cultures and backgrounds, will be necessary to establish the boundary conditions of our observed effects. Further, we employed aggression tasks that may not directly replicate the phenomenology of a 'real-world' act of aggression. As such, our findings are constrained to the context of our aggression tasks and future ecological momentary assessment will be needed to test whether our findings replicate for acts of 'real-world' 
aggression.

Self-reported correlations. Inferences were based on correlational findings obtained from self-reported affective states. As such, we cannot claim that instability (or a lack thereof) in certain affective states caused greater aggression. Further, it is unclear if participants' self-reports of affect accurately mapped on to their actual experiences or if they were biased by recall errors and bias. Future experimental manipulations of affective states alongside aggressive acts could allow for causal inferences that are assumed to be uninfluenced by self-report biases.

Motivation. Aggression's affective bases are also heavily contingent on their motivational properties. Whereas anger (a negatively-valenced, approach-motivated state) magnifies aggression (Harmon-Jones, 2003), disgust (a negatively-valenced, avoidance-motivated state) inhibits aggression (Pond et al., 2012). We did not examine this variable and future research is needed to test how momentary fluctuations in such motivational states around aggressive acts contributes to their severity.

Redundancy in aggression measurement. Aggression was measured using both behaviors from a given task and self-reported traits. These two metrics may have largely been redundant as both were assessed in a between-participants fashion. As such, between-participant variability in trait aggression may have also been reflected in between-participant variability in aggressive behavior. Future research should assess aggressive behavior longitudinally to disentangle within- and between-participant variability and its effects on aggression-related affect.

Timing. Our 'during aggression' assessments of negative and positive affect were completed by participants retrospectively, after they had completed the aggression 
task. As such, these retrospective reports may have biased our results. However, retrospective affect reports match closely with reports provided during the actual affecteliciting experience (Harmon-Jones, Bastian, \& Harmon-Jones, 2016). Future work in this domain may benefit from other psychometric approaches such as continuous affect rating systems that are acquired throughout laboratory tasks.

\section{Conclusions}

Across eight studies and against our predictions, aggressive behavior and dispositions were linked to less variability in positive affect surrounding an opportunity to be aggressive. These findings suggest that affective instability is not always a risk factor for aggression and that stability may sometimes underlie such hostility. We hope that future work will build upon these findings, investigating the ways in which dynamics changes or stability in affect can lead to violence and building interventions that harness these mechanisms to reduce human violence. 


\section{References}

Anderson, C. A. \& Bushman, B. J. (2002). Human aggression. Annual Review of Psychology, 53, 27-51.

Barrett, L. F. (2009). Variety is the spice of life: A psychological construction approach to understanding variability in emotion. Cognition and Emotion, 23, 1284-1306.

Barrett, L. F. \& Bliss-Moreau, E. (2009). Affect as a psychological primitive. Advances in Experimental Social Psychology, 41, 167-218.

Barrett, L. F. \& Russell, J. A. (1999). The structure of current affect: Controversies and emerging consensus. Current Directions in Psychological Science, 8, 10-14.

Berkowitz, L. (1989). Affective aggression: The role of stress, pain, and negative affect. In R. G. Geen \& E. Donnerstein (Eds.), Human aggression: theories, research, and implications for social policy (pp. 49-72). San Diego, CA: Academic Press.

Bushman, B. J. (2002). Does venting anger feed or extinguish the flame? Catharsis, rumination, distraction, anger, and aggressive responding. Personality and social psychology bulletin, 28, 724-731.

Buss, A. H. \& Perry, M. (1992). The aggression questionnaire. Journal of Personality and Social Psychology, 63, 452-459.

Capaldi, E. (1966). Partial reinforcement. Psychological Review, 73, 459-477.

Chester, D. S. (2017). The role of positive affect in aggression. Current Directions in Psychological Science, 26, 366-370.

Chester, D.S. \& Dzierzewski, J.M. (in press). Sour sleep, sweet revenge? Aggressive pleasure as a potential mechanism underlying poor sleep quality's link to aggression. Emotion. 
Chester, D. S. \& DeWall, C. N. (2016). The pleasure of revenge: Retaliatory aggression arises from a neural imbalance toward reward. Social Cognitive and Affective Neuroscience, 11, 1173-1182.

Chester, D. S. \& DeWall, C. N. (2017). Combating the sting of rejection with the pleasure of revenge: A new look at how emotion shapes aggression. Journal of Personality and Social Psychology, 112, 413-430.

Chester, D. S., DeWall, C. N., \& Enjaian, B. (2019). Sadism and aggressive behavior: Inflicting pain to feel pleasure. Personality and Social Psychology Bulletin, 45, $1252-1268$.

Chester, D. S. \& Lasko, E. N. (2019). Validating a standardized approach to the Taylor Aggression Paradigm. Social Psychological and Personality Science, 10, 620631.

Chester, D. S., Lynam, D. R., Milich, R., \& DeWall, C. N. (2018). Neural mechanisms of the rejection-aggression link. Social Cognitive and Affective Neuroscience, 13, 501-512.

Chou, C. P., Yang, D., Pentz, M. A., \& Hser, Y. I. (2004). Piecewise growth curve modeling approach for longitudinal prevention study. Computational Statistics \& Data Analysis, 46, 213-225.

Cohn, A. M., Zeichner, A., \& Seibert, L. A. (2008). Labile affect as a risk factor for aggressive behavior in men. Psychology of Men \& Masculinity, 9, 29-39.

Curran, P. J. \& Hussong, A. M. (2009). Integrative data analysis: The simultaneous analysis of multiple data sets. Psychological Methods, 14, 81-100.

Denson, T. F., Capper, M. M., Oaten, M., Friese, M., \& Schofield, T. P. (2011). Self- 
control training decreases aggression in response to provocation in aggressive individuals. Journal of Research in Personality, 45, 252-256.

Denson, T. F., DeWall, C. N., \& Finkel, E. J. (2012). Self-control and aggression. Current Directions in Psychological Science, 21, 20-25.

DeWall, C. N., Finkel, E. J., Lambert, N. M., Slotter, E. B., Bodenhausen, G. V., Pond, R. S., ... Fincham, F. D. (2013). The voodoo doll task: Introducing and validating a novel method for studying aggressive inclinations. Aggressive Behavior, 39, 419-439.

DeWall, C. N., Lambert, N. M., Pond Jr, R. S., Kashdan, T. B., \& Fincham, F. D. (2012). A grateful heart is a nonviolent heart: Cross-sectional, experience sampling, longitudinal, and experimental evidence. Social Psychological and Personality Science, 3, 232-240.

Diener, E. (2013). Scale of Positive and Negative Experience (SPANE). Measurement Instrument Database for the Social Science. Retrieved from http://www.midss.org/content/scale-positive-and-negative-experience-spane-0

Edmondson, D., Shaffer, J. A., Chaplin, W. F., Burg, M. M., Stone, A. A., \& Schwartz, J. E. (2013). Trait anxiety and trait anger measured by ecological momentary assessment and their correspondence with traditional trait questionnaires. Journal of Research in Personality, 47, 843-852.

Finkel, E. J., DeWall, C. N., Slotter, E. B., McNulty, J. K., Pond, J. R., \& Atkins, D. C. (2012). Using $\mathrm{I}^{3}$ theory to clarify when dispositional aggressiveness predicts intimate partner violence perpetration. Journal of Personality and Social Psychology, 102, 533-549. 
Gilam, G., Abend, R., Shani, H., Ben-Zion, Z., \& Hendler, T. (2019). The anger-infused ultimatum game: A reliable and valid paradigm to induce and assess anger. Emotion, 19, 84-96.

Gilam, G., Lin, T., Raz, G., Azrielant, S., Fruchter, E., Ariely, D., \& Hendler, T. (2015). Neural substrates underlying the tendency to accept anger-infused ultimatum offers during dynamic social interactions. Neurolmage, 120, 400-411.

Harmon-Jones, E. (2003). Anger and the behavioral approach system. Personality and Individual Differences, 35, 995-1005.

Harmon-Jones, C., Bastian, B., \& Harmon-Jones, E. (2016). The discrete emotions questionnaire: A new tool for measuring state self-reported emotions. PloS ONE, 11(8), e0159915.

Hyatt, C., Zeichner, A., \& Miller, J. (2019). Laboratory aggression and personality traits: A meta-analytic review. Psychology of Violence, 9(6), 675-689.

Kashdan, T. B., DeWall, C. N., Pond, R. S., Silvia, P. J., Lambert, N. M., Fincham, F. D., ... \& Keller, P. S. (2013). Curiosity protects against interpersonal aggression: Cross-sectional, daily process, and behavioral evidence. Journal of Personality, 81, 87-102.

Koenigsberg, H. W., Harvey, P. D., Mitropoulou, V., New, A. S., Goodman, M., Silverman, J., ... \& Siever, L. J. (2001). Are the interpersonal and identity disturbances in the borderline personality disorder criteria linked to the traits of affective instability and impulsivity? Journal of Personality Disorders, 15, 358370.

Kuppens, P., Van Mechelen, I., Nezlek, J. B., Dossche, D., \& Timmermans, T. (2007). 
Individual differences in core affect variability and their relationship to personality and psychological adjustment. Emotion, 7, 262-274.

Liu, Y., Liu, H., Li, H., \& Zhao, Q. (2015). The effects of individually varying times of observations on growth parameter estimations in piecewise growth model. Journal of Applied Statistics, 42, 1843-1860

McNulty, J. K. \& Hellmuth, J. C. (2008). Emotion regulation and intimate partner violence in newlyweds. Journal of Family Psychology, 22, 794-797.

Mead, N. L., Baumeister, R. F., Gino, F., Schweitzer, M. E., \& Ariely, D. (2009). Too tired to tell the truth: Self-control resource depletion and dishonesty. Journal of Experimental Social Psychology, 45, 594-597.

Miles, S. R., Tharp, A. T., Stanford, M., Sharp, C., Menefee, D., \& Kent, T. A. (2015). Emotion dysregulation mediates the relationship between traumatic exposure and aggression in healthy young women. Personality and Individual Differences, 76, 222-227.

Moskowitz, D. S., \& Zuroff, D. C. (2004). Flux, pulse, and spin: dynamic additions to the personality lexicon. Journal of Personality and Social Psychology, 86, 880-893.

Pond, R. S., DeWall, C. N., Lambert, N. M., Deckman, T., Bonser, I. M., \& Fincham, F. D. (2012). Repulsed by violence: Disgust sensitivity buffers trait, behavioral, and daily aggression. Journal of Personality and Social Psychology, 102, 175-188.

Preacher, K. J., Curran, P. J., \& Bauer, D. J. (2006). Computational tools for probing interaction effects in multiple linear regression, multilevel modeling, and latent curve analysis. Journal of Educational and Behavioral Statistics, 31, 437-448.

Ramirez, J. M., \& Andreu, J. M. (2006). Aggression, and some related psychological 
constructs (anger, hostility, and impulsivity): Some comments from a research project. Neuroscience \& Biobehavioral Reviews, 30, 276-291.

Richard, F. D., Bond Jr, C. F., \& Stokes-Zoota, J. J. (2003). One hundred years of social psychology quantitatively described. Review of General Psychology, 7, 331-363.

Riva, P., Wirth, J. H., \& Williams, K. D. (2011). The consequences of pain: The social and physical pain overlap on psychological responses. European Journal of Social Psychology, 41, 681-687.

Röll, J., Koglin, U., \& Petermann, F. (2012). Emotion regulation and childhood aggression: Longitudinal associations. Child Psychiatry \& Human Development, 43, 909-923.

Rosen, P. J. \& Factor, P. I. (2015). Emotional impulsivity and emotional and behavioral difficulties among children with ADHD: An ecological momentary assessment study. Journal of Attention Disorders, 19, 779-793.

Russell, J. A. (2003). Core affect and the psychological construction of emotion. Psychological Review, 110, 145-172.

Scott, L. N., Wright, A. G., Beeney, J. E., Lazarus, S. A., Pilkonis, P. A., \& Stepp, S. D. (2017). Borderline personality disorder symptoms and aggression: A withinperson process model. Journal of Abnormal Psychology, 126, 429-440.

Taylor, S. (1967). Aggressive behavior and physiological arousal as a function of provocation and the tendency to inhibit aggression. Journal of Personality, 35, 297-310.

Tellegen, A., Watson, D., \& Clark, L. A. (1999). On the dimensional and hierarchical structure of affect. Psychological Science, 10, 297-303. 
Thielmann, I., Spadaro, G., \& Balliet, D. (in press). Personality and prosocial behavior: A theoretical framework and meta-analysis. Psychological Bulletin.

Van Beest, I. \& Williams, K. D. (2006). When inclusion costs and ostracism pays, ostracism still hurts. Journal of Personality and Social Psychology, 91, 918-928.

Webster, G. D., DeWall, C. N., Pond, R. S., Deckman, T., Jonason, P. K., Le, B. M., ... \& Smith, C. V. (2014). The brief aggression questionnaire: Psychometric and behavioral evidence for an efficient measure of trait aggression. Aggressive Behavior, 40, 120-139.

Wilkowski, B. M., \& Robinson, M. D. (2010). The anatomy of anger: An integrative cognitive model of trait anger and reactive aggression. Journal of Personality, 78, 9-38.

Williams, K. D. (2009). Ostracism: A temporal need-threat model. In Mark P. Zanna (Ed.), Advances in experimental social psychology (pp. 275-314). Cambridge, MA: Academic Press.

Williams, K. D., Cheung, C. T, K., \& Choi, W. (2000). Cyberostracism: Effects of being ignored over the Internet. Journal of Personality and Social Psychology, 79, 748762.

Williams, K. D., Yeager, D. S., Cheung, C. K. T., \& Choi, W. (2012). Cyberball (version 4.0) [Software]. Available from https://cyberball.wikispaces.com.

Wright, A. G., Stepp, S. D., Scott, L. N., Hallquist, M. N., Beeney, J. E., Lazarus, S. A., \& Pilkonis, P. A. (2017). The effect of pathological narcissism on interpersonal and affective processes in social interactions. Journal of Abnormal Psychology, 126, 898-910. 
Zillmann, D., Katcher, A. H., \& Milavsky, B. (1972). Excitation transfer from physical exercise to subsequent aggressive behavior. Journal of Experimental Social Psychology, 8, 247-259.

Supplemental Table 1. Component loadings from the principal components analysis of Need Threat Scale affect subscale items across all eight studies. Bold values represent items that were included in each component.

\begin{tabular}{lclcccc}
\hline NTS Item & $\begin{array}{l}\text { Factor 1 } \\
\text { (Pre) }\end{array}$ & $\begin{array}{l}\text { Factor 2 } \\
\text { (Pre) }\end{array}$ & $\begin{array}{l}\text { Factor 1 } \\
\text { (During) }\end{array}$ & $\begin{array}{l}\text { Factor 2 } \\
\text { (During) }\end{array}$ & $\begin{array}{l}\text { Factor 1 } \\
\text { (Post) }\end{array}$ & $\begin{array}{l}\text { Factor 2 } \\
\text { (Post) }\end{array}$ \\
\hline Good & .90 & -.14 & .92 & .00 & .91 & -.11 \\
Bad & -.19 & .89 & -.14 & .87 & -.18 & .87 \\
Angry & -.06 & .88 & .20 & .77 & .03 & .86 \\
Pleasant & .91 & -.09 & .93 & .04 & .92 & -.05 \\
Happy & .93 & -.10 & .94 & .05 & .94 & -.07 \\
Sad & -.08 & .87 & .02 & .86 & -.09 & .89 \\
\hline
\end{tabular}


Supplemental Table 2. Cronbach's alphas from Need Threat Scale affect subscale items across all eight studies.

\begin{tabular}{lllllll}
\hline Statistic & $\begin{array}{l}\text { Positive } \\
\text { (Pre) }\end{array}$ & $\begin{array}{l}\text { Negative } \\
\text { (Pre) }\end{array}$ & $\begin{array}{l}\text { Positive } \\
\text { (During) }\end{array}$ & $\begin{array}{l}\text { Negative } \\
\text { (During) }\end{array}$ & $\begin{array}{l}\text { Positive } \\
\text { (Post) }\end{array}$ & $\begin{array}{l}\text { Negative } \\
\text { (Post) }\end{array}$ \\
\hline$\alpha$ & .91 & .86 & .93 & .78 & .92 & .85 \\
\hline
\end{tabular}

